\title{
Effects of Light and Dark on the Ultrastructure of Lichen Algae
}

\author{
D. H. BROWN*, C. ASCASO $\dagger$ and S. RAPSCH $\dagger$ \\ Department of Botany, The University, Bristol BS8 1UG, UK* and Instituto de Edafologia y Biologia Vegetal, \\ C.S.I.C., Serrano 115 bis, 28006 Madrid, Spain $\dagger$
}

Accepted: 7 July 1988

\begin{abstract}
Quantitative ultrastructural observations have been made on the algal cells (Trebouxia) in two lichens, Parmelia sulcata and P. laevigata, stored for $48 \mathrm{~h}$ in the dark or under a light/dark regime. The response of the alga was found to differ in these lichens. In P. sulcata the dark treatment caused a decrease in starch grains, lipid-rich pyrenoglobuli and peripheral cytoplasmic storage bodies and an increase in pyrenoid and chloroplast protein bodies. The algae in $P$. laevigata contained little starch and no chloroplast protein bodies. However, after dark treatment, starch, cytoplasmic storage bodies and pyrenoid dimensions sometimes declined, while pyrenoglobuli numbers increased. Some of these apparent changes depended upon the units used for calculating the cross-sectional areas of structures, e.g. absolute units, percentage of cell wall, protoplast or chloroplast cross-sectional area. Chloroplast area increased in the dark (as a \% of cell wall area) in both species while mitochondria were larger in the dark in P. sulcata but not in $P$. laevigata. Ultrastructural changes were not clearly correlated with changes in photosynthetic and respiratory rates. These results directly support the suggestion that some intra-cellular structures are energy-generating reserves the dimensions of which can rapidly change.
\end{abstract}

Key words: Parmelia sulcata, Parmelia laevigata, lichen algae, light and dark storage, starvation, reserve substances, organelle dimensions.

\section{INTRODUCTION}

Lichen algae contain a number of structures which may act as reserves of energy-generating chemicals. Thus, chloroplasts may contain starch grains and lipid-rich pyrenoglobuli, in addition to the proteinaceous pyrenoid, and osmiophilic 'storage bodies' frequently occur beneath the plasma membrane within the cytoplasm (Jacobs and Ahmadjian, 1969; Ahmadjian, 1982; Holopainen, 1982; Scott and Larson, 1984; Ascaso, Brown and Rapsch, 1986). Little direct information is available to demonstrate that these structures actually represent materials which may be utilized under conditions of stress. Changes in the appearance and number of many of these structures have been reported in isolated Trebouxia at different light intensities (Fisher and Lang, 1971), or with an added organic carbon source (Jacobs and Ahmadjian, 1971). In intact lichens, such changes have been observed at different times of the year (Ascaso and Galvan, 1976; Holopainen, 1982) or following stresses, such as desiccation (see references in
Ahmadjian, 1982; Ascaso et al., 1986, 1988). Recent work has shown that some of these changes, rather than reflecting the consequences of longterm physiological adjustments, may be rapidly induced during storage under controlled conditions (Ascaso et al., 1986, 1988). With the introduction of quantitative methods for the study of cellular structures, it is now possible to investigate more directly the possible reserve nature of many of these components (Ascaso et al., 1985, 1986, 1988; Brown, Ascaso and Rapsch, 1987).

Starch synthesis has been correlated with the incubation of lichens at intermediate thallus water contents. It has been suggested that, compared to fully hydrated material, a smaller proportion of photosynthetic products is released from the algal to the fungal symbiont so that more is retained and converted to starch (Harris and Kershaw, 1971; Macfarlane and Kershaw, 1982; Ascaso et al., 1986). While starch increases in senescent algal cells, probably also due to reduced translocation to fungal cells (Scott and Larson, 1984), the loss of 
starch has not previously been investigated in either senescent or undamaged material.

Changes in pyrenoglobuli have also been related to desiccation stress. Although not an invariable observation, the movement of pyrenoglobuli to the periphery of the pyrenoid under desiccating conditions has been frequently commented upon (see Ahmadjian, 1982; Ascaso et al., 1986 for references). It has been suggested that this may sometimes merely reflect desiccation-induced changes in the protein matrix of the pyrenoid (Ascaso and Galvan, 1976; Brown et al., 1987). Ascaso et al. (1986) suggested that there was no clear evidence of the utilization of pyrenoglobuli during short-term desiccation experiments using Trebouxia in Lasallia pustulata. They showed that, while pyrenoglobuli numbers decreased on desiccation, their cross-sectional area increased so that the proportion of the pyrenoid matrix which they occupied remained constant. Ascaso et al. (1988) found that pyrenoglobuli numbers, in Trebouxia, altered to a greater extent during rehydration than during desiccation in the more desiccation sensitive Parmelia laevigata.

Peripheral 'storage bodies' have been reported to be larger and more lightly staining in two Trebouxia-containing lichens during the dry spring/summer months (Holopainen, 1982). Ascaso et al. (1986) showed that brief desiccation stress of Lobaria amplissima decreased the numbers of 'storage bodies' in the alga Myrmecia but increased their average cross-sectional area. It is not clear whether staining density can be used as a measure of the amount of material within a storage body. Ascaso et al. (1988) considered the lighter colour of some lipoidal bodies may only reflect their position relative to the plane of the section and Ascaso et al. (1985) related staining of storage bodies to the phosphate content of the fixative buffer.

The work reported here was performed to observe what changes occurred in structures previously implied to have a storage function, following relatively short periods of incubation in the light, when photosynthetic products could be formed, or in the dark, when respiratory processes might be expected to cause the utilization of energy-generating reserves. Consideration is also given to the problem of choosing appropriate numerical methods of expressing morphometric data in order to obtain biologically valid comparisons. Two epiphytic species from the same genus, whose geographical distribution patterns apparently reflect different desiccation sensitivities, were investigated.

\section{MATERIALS AND METHODS}

\section{Storage}

Parmelia laevigata $(\mathrm{Sm}$.$) Ach. was collected from$ Holne Woods, near Ashburton, Devon and Parmelia sulcata Taylor from Chagford, Devon. Material was transported to the laboratory in polythene bags and stored in a moist condition for $2 \mathrm{~d}$ on a $12 \mathrm{~h}$ light $\left(135 \mu \mathrm{mol} \mathrm{m}^{-2} \mathrm{~s}^{-1}, 20^{\circ} \mathrm{C}\right): 12 \mathrm{~h}$ dark $\left(14^{\circ} \mathrm{C}\right)$ regime.

Excised $1 \mathrm{~cm}$ lobe tips were transferred, $3 \mathrm{~h}$ into the light period, to transparent containers at $100 \%$ r.h. in $(a)$ the dark or $(b)$ a light $\left(250 \mu \mathrm{mol} \mathrm{m}^{-2} \mathrm{~s}^{-1}\right) /$ dark regime. Both treatments involved the above, alternating, temperature conditions. Samples were fixed after $3 \mathrm{~d}$ incubation, the light/dark samples being fixed $3 \mathrm{~h}$ after illumination commenced.

\section{Fixation}

Samples, taken 2-3 mm behind the lobe margin from 2-4 thalli, were vacuum infiltrated and fixed in $3.125 \%$ glutaraldehyde in $0.05 \mathrm{M}$ phosphate buffer, $\mathrm{pH} 7 \cdot 1$, for $3 \mathrm{~h}$ at $4{ }^{\circ} \mathrm{C}$. Samples were washed in phosphate buffer overnight at $4{ }^{\circ} \mathrm{C}$, post-fixed in $1 \%$ osmium tetroxide for $3 \mathrm{~h}$, dehydrated in ethanol and embedded in Spurr's (1969) resin. Specimens were sectioned, stained with lead citrate (Reynolds, 1963) and observed in a Philips E.M. 300 electron microscope.

\section{Measurements}

A MOP-Videoplan (Kontron) semi-automatic digitizing image analysis system was used to quantify changes in pyrenoid dimensions. Measurements were made on 30 sections, taken from 2-3 resin blocks, in which pyrenoids were visible. Data are presented \pm the s.e.

TABLE 1. Photosynthetic and respiratory rates in Parmelia sulcata and Parmelia laevigata after $D$ or $L / D$ treatment

\begin{tabular}{|c|c|c|c|}
\hline \multirow[b]{2}{*}{ Species } & \multirow[b]{2}{*}{ Condition } & \multicolumn{2}{|c|}{ ppm $\mathrm{CO}_{2} \min ^{-1} \mathrm{gd} . \mathrm{wt}^{-1}$} \\
\hline & & $\begin{array}{l}\text { Photosynthetic } \\
\text { rate }\end{array}$ & $\begin{array}{l}\text { Respiratory } \\
\text { rate }\end{array}$ \\
\hline P. sulcata & $\begin{array}{l}\mathrm{L} / \mathrm{D} \\
\mathrm{D}\end{array}$ & $\begin{array}{l}-0.428 \pm 0.187 * \\
-0.464 \pm 0.170\end{array}$ & $\begin{array}{l}0.295 \pm 0.085 \\
0.332 \pm 0.096\end{array}$ \\
\hline P. laevigata & $\begin{array}{l}\mathrm{L} / \mathrm{D} \\
\mathrm{D}\end{array}$ & $\begin{array}{l}-0.459 \pm 0.083 \\
-0.473 \pm 0.025\end{array}$ & $\begin{array}{l}0 \cdot 112 \pm 0.023 \\
0 \cdot 150 \pm 0.001\end{array}$ \\
\hline
\end{tabular}

* s.d. $n=2$. 

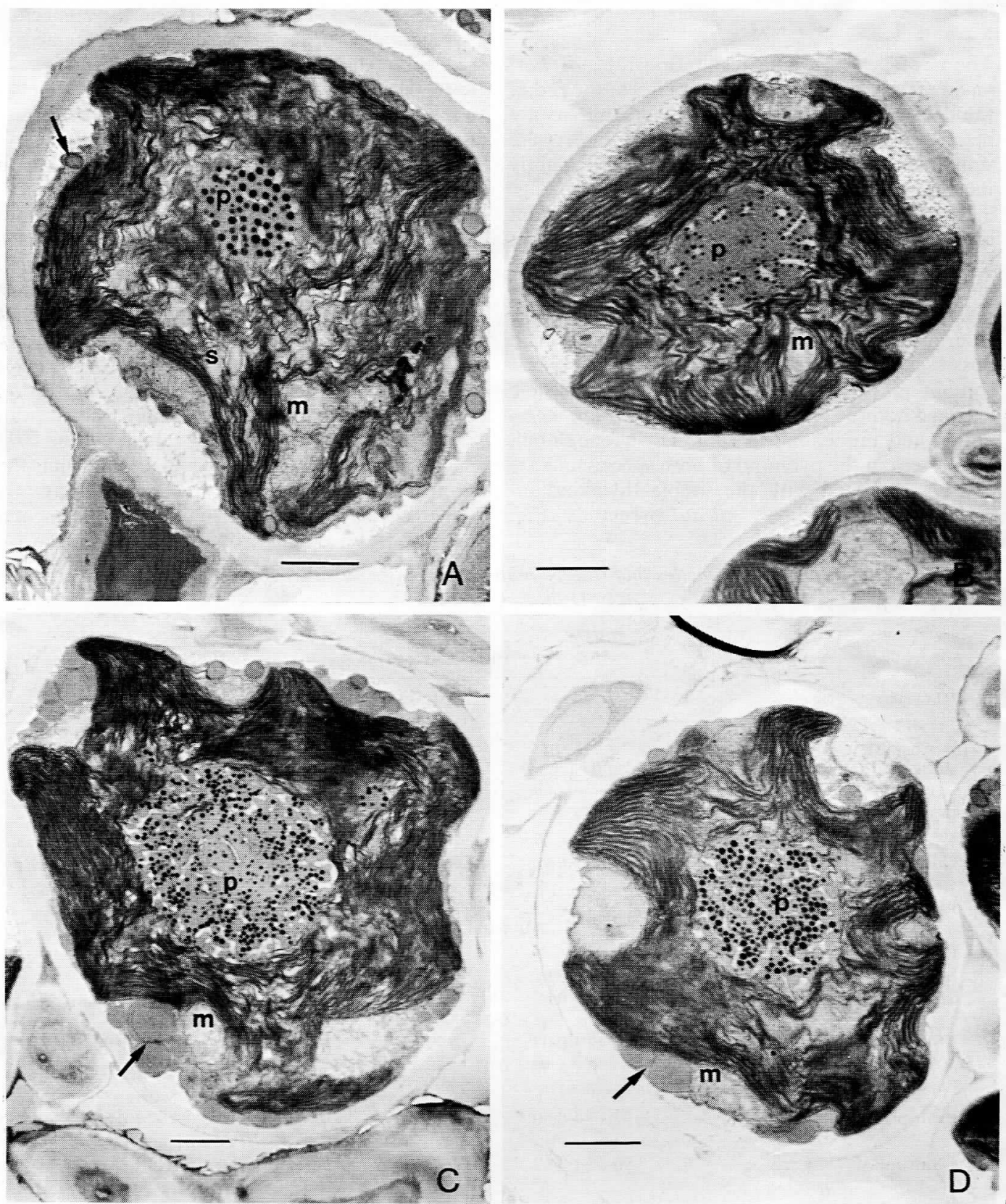

Fig. 1. Electron micrographs of algal cells from (A, B) Parmelia sulcata and (C, D) Parmelia laevigata. Samples stored in alternating light/dark (A, C) or dark (B, D) regimes, Bar $=1 \mu \mathrm{m}$. Arrow $=$ storage body, $\mathrm{c}=$ chloroplast, $\mathrm{p}=$ pyrenoid, $\mathrm{m}=$ mitochondrion

Gas exchange measurements

Lichen respiration and photosynthesis was determined by infra-red gas analysis, changes in $\mathrm{CO}_{2}$ concentration in sealed glass bottles being measured at $18^{\circ} \mathrm{C}$ by the method of Snelgar, Brown and Green (1980). 


\section{RESULTS}

The photosynthetic and respiration rates of Parmelia sulcata and $P$. laevigata samples at the end of the dark (D) or light/dark (L/D) treatments are recorded in Table 1 . Photosynthetic rates were similar in both species and were very slightly increased after the D treatment, the percentage increase being greater in $P$. sulcata. Respiration rates were lower in $P$. laevigata than $P$. sulcata, but the $\mathrm{D}$ treatment caused a greater percentage increase in the former species.

Both $P$. sulcata and $P$. laevigata contain the chlorophycean algal genus Trebouxia which possesses a large centrally placed chloroplast containing a substantial pyrenoid, cytoplasmic 'storage bodies' located beneath its plasma membrane, and mitochondria (Fig. 1). Pyrenoglobuli are present in the pyrenoid of both species and are clearly associated with the simple thylakoid invaginations found in $P$. sulcata pyrenoids (Fig.
1 A, B) (Brown et al., 1987). The larger number of pyrenoglobuli in P. laevigata (Fig. 1C, D) are not so clearly related to the thylakoid reticulum present in this species (Ascaso et al., 1988). P. laevigata has a more oceanic distribution in the British Isles and is considered to be a more desiccation-sensitive species than the more ubiquitous $P$. sulcata (Ascaso et al., 1988).

Data in Table 2 show the dimensions of various cellular features in samples of the two Parmelia species after storage in the L/D (Fig. 1 A, C) or D (Fig. 1 B, D) conditions. Two modes of expression are presented; (1) in absolute units and (2) expressing the cross-sectional area of structure as a percentage of the cross-sectional area of the inner surface of the cell wall. The latter expression compensates for the substantially larger wall circumference (and hence cell volume) in the L/D incubated samples. Expressed in absolute units the protoplast dimensions were greater in $\mathrm{L} / \mathrm{D}$ samples but equal in $P$. laevigata or lower in $P$. sulcata,

TA BLE 2. Dimensions of organelles and reserve material in Parmelia sulcata and Parmelia laevigata after $D$ or $L / D$ treatment

\begin{tabular}{|c|c|c|c|c|}
\hline \multirow[b]{2}{*}{ Structure } & \multicolumn{2}{|c|}{ P. laevigata } & \multicolumn{2}{|c|}{ P. sulcata } \\
\hline & $\mathrm{D}$ & $\mathrm{L} / \mathrm{D}$ & $\mathrm{D}$ & $\mathrm{L} / \mathrm{D}$ \\
\hline \multicolumn{5}{|c|}{ (a) Absolute units $\mu \mathrm{m}^{2}$} \\
\hline Wall area & \multicolumn{2}{|c|}{$\begin{array}{c}24.93 \pm 1.12 \\
P<0.01 \dagger\end{array}$} & $29 \cdot 77 \pm 1 \cdot 46$ & $33 \cdot 31 \pm 2 \cdot 23$ \\
\hline Protoplast & \multicolumn{2}{|c|}{$P<0.01$} & $27 \cdot 73 \pm 1 \cdot 39$ & $29.98 \pm 2.04$ \\
\hline Chloroplast & \multicolumn{2}{|c|}{$P<0.01$} & $23 \cdot 38 \pm 1 \cdot 24$ & $23.93 \pm 1 \cdot 61$ \\
\hline Pyrenoid & \multicolumn{2}{|c|}{$P<0.01$} & $3 \cdot 20 \pm 0 \cdot 27$ & $2 \cdot 87 \pm 0 \cdot 24$ \\
\hline Protein bodies & 0 & 0 & $0 \cdot 09 \pm 0.04$ & $0.08 \pm 0.04$ \\
\hline Starch & $0.01 \pm 0.01$ & $0.02 \pm 0.06$ & 0 & $0.46 \pm 0.06$ \\
\hline Storage bodies & \multicolumn{2}{|c|}{$P<0.01$} & \multicolumn{2}{|c|}{$P<0.01$} \\
\hline Mitochondria & $\begin{array}{r}0 \cdot 49 \pm 0 \cdot 07 \\
P<\end{array}$ & $P<0.01$ & $0.73 \pm 0.97$ & $0.59 \pm 0.07$ \\
\hline \multicolumn{5}{|l|}{ (b) $\%$ of wall area } \\
\hline Protoplast & $91 \cdot 17 \pm 0 \cdot 50$ & $91 \cdot 56 \pm 0 \cdot 73$ & \multicolumn{2}{|c|}{$P<0.01$} \\
\hline Chloroplast & $79 \cdot 45 \pm 0 \cdot 69$ & $76 \cdot 77 \pm 1 \cdot 53$ & \multicolumn{2}{|c|}{$P<0.01$} \\
\hline Pyrenoid & $12 \cdot 50 \pm 0 \cdot 65$ & $12 \cdot 30 \pm 0 \cdot 71$ & $\begin{array}{r}10 \cdot 74 \pm 0 \cdot 66 \\
P\end{array}$ & $0 \cdot 01$ \\
\hline Protein bodies & 0 & 0 & $0 \cdot 28 \pm 0 \cdot 14$ & $0 \cdot 22 \pm 0 \cdot 11$ \\
\hline Starch & $0.03 \pm 0.01$ & $0.04 \pm 0.02$ & 0 & $1 \cdot 39 \pm 0.19$ \\
\hline Storage bodies & $0 \cdot 02 \pm 0.01$ & $0.03 \pm 0.01$ & $0.01 \pm 0.01$ & $0.02 \pm 0.01$ \\
\hline Mitochondria & $\begin{array}{r}P \\
2 \cdot 00 \pm 0 \cdot 28\end{array}$ & $2 \cdot 79 \pm 0 \cdot 23$ & $\begin{array}{r}P \\
2.55 \pm 0 \cdot 29 \\
P\end{array}$ & 0.01 \\
\hline
\end{tabular}

* s.e. $†$ Student's $t$ test. $n=30$. 

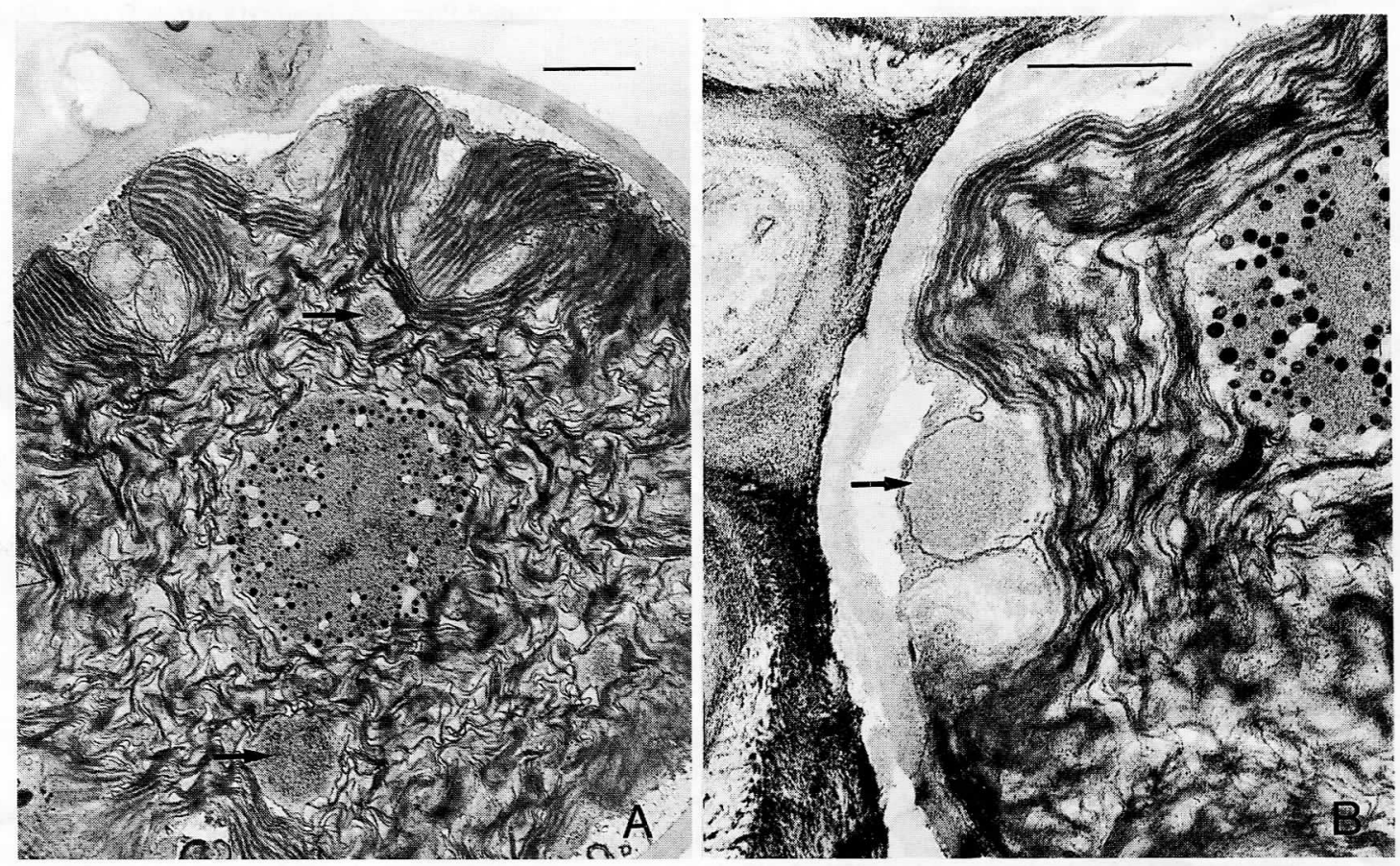

FIG. 2. Electron micrographs of algal cells from dark stored Parmelia sulcata, showing (arrow) protein bodies in the chloroplast. Bar $=1 \mu \mathrm{m}$.

when corrected for differences in wall dimension. The corrected values show smaller chloroplasts in L/D samples in both species, where uncorrected values show $\mathrm{D}$ chloroplast dimensions to be smaller in $P$. laevigata and equal in $P$. sulcata. A similar correction based on the protoplast area confirmed the smaller chloroplasts after L/D storage in both species $(P$. laevigata $\mathrm{D}=87 \cdot 14 \% \pm 0 \cdot 56, \mathrm{~L} / \mathrm{D}=$ $83.78 \% \pm 1 \cdot 34 ; \quad P$. sulcata $\mathrm{D}=84 \cdot 14 \% \pm 0 \cdot 78$, $\mathrm{L} / \mathrm{D}=79 \cdot 95 \% \pm 0 \cdot 95$ )

Mitochondria in P. laevigata were always larger after the L/D treatment, irrespective of mode of calculation, while in $P$. sulcata they were somewhat larger under the D treatment. These differences were only statistically valid for $P$. laevigata in absolute terms and for $P$. sulcata on a percent wall area basis.

In $P$. laevigata the uncorrected pyrenoid dimensions appear larger in the L/D treatment, but after correction for wall dimensions (Table 2) or protoplast area $(\mathrm{D}=13.72 \% \pm 0.72, \quad \mathrm{~L} / \mathrm{D}=$ $13.47 \% \pm 0.79)$ this difference disappeared. However, expressing the pyrenoid dimensions per unit area of the chloroplast suggests a slightly larger pyrenoid in the $\mathrm{L} / \mathrm{D}(16.36 \% \pm 1 \cdot 13)$ rather than
D treatment $(15 \cdot 79 \% \pm 0 \cdot 84)$, but this is not statistically significant. In $P$. sulcata, uncorrected pyrenoid dimensions suggest the reverse situation, larger in $\mathrm{D}$ than $\mathrm{L} / \mathrm{D}$ conditions, and this is sustained when calculated on a wall area basis (Table 2), protoplast area basis ( $D=11.58 \%$ $\pm 0.72, \mathrm{~L} / \mathrm{D}=9.40 \% \pm 0.42$ ) or chloroplast basis $(\mathrm{D}=13.78 \% \pm 0.86, \mathrm{~L} / \mathrm{D}=11.78 \% \pm 0.51)$. The chloroplast of $P$. sulcata contains, in addition to the pyrenoid, a number of presumed proteinaceous bodies within its stroma which are not membrane bounded (Fig. 2). The total area of these bodies was slightly larger in the D treatment, irrespective of the method of calculation. The combined area of insoluble protein (pyrenoid plus protein bodies) was thus larger in the $\mathrm{D}$ treatment in this species. No such protein bodies have been detected in the chloroplast of $P$. laevigata, and hence the pyrenoid remains, potentially, the main protein reserve in the chloroplast and/or cell.

Cytoplasmic 'storage bodies' were present in both Parmelia species. In both cases they appeared to occupy a larger proportion of the cell following L/D treatment. In $P$. laevigata this difference disappeared when areas were calculated on a wall 
TA BLE 3. Values of pyrenoglobuli numbers in Parmelia sulcata and Parmelia laevigata after $D$ or $L / D$ treatment

\begin{tabular}{|c|c|c|c|c|}
\hline \multirow[b]{2}{*}{ Pyrenoglobuli } & \multicolumn{2}{|c|}{ P. laevigata } & \multicolumn{2}{|c|}{ P. sulcata } \\
\hline & $\mathrm{D}$ & $\mathrm{L} / \mathrm{D}$ & $\mathrm{D}$ & $\mathrm{L} / \mathrm{D}$ \\
\hline \multicolumn{5}{|l|}{ (a) Absolute units $\mu \mathrm{m}^{2}$} \\
\hline & $220 \cdot 57 \pm 17 \cdot 30^{*}$ & $218 \cdot 10 \pm 19 \cdot 27$ & \multicolumn{2}{|c|}{$\begin{array}{c}85.60 \pm 5.99 \quad 166 \cdot 10 \pm 12 \cdot 25 \\
P<0.01 \dagger\end{array}$} \\
\hline (b) $\%$ of wall area & \multicolumn{2}{|c|}{$\begin{array}{r}8.71 \pm 0.53 \\
P\end{array}$} & \multicolumn{2}{|c|}{$P<0.01$} \\
\hline (c) $\%$ of protoplast area & \multicolumn{2}{|c|}{$P<0.01$} & \multicolumn{2}{|c|}{$P<0.01$} \\
\hline (d) $\%$ of chloroplast area & $11 \cdot 01 \pm 0 \cdot 68$ & $7 \cdot 83 \pm 0.51$ & $3 \cdot 73 \pm 0 \cdot 20$ & $7 \cdot 04 \pm 0 \cdot 39$ \\
\hline (e) $\%$ of pyrenoid area & $\begin{aligned} P & <0 \\
68.91 \pm 2.59 & \\
P & <0\end{aligned}$ & $48 \cdot 31 \pm 1 \cdot 71$ & $\begin{array}{r}P \\
28.43 \pm 1 \cdot 24 \\
P\end{array}$ & $\begin{array}{l}59 \cdot 68 \pm 2 \cdot 15 \\
5 \cdot 01\end{array}$ \\
\hline
\end{tabular}

${ }^{*}$ s.e. $\dagger$ Student's $t$ test. $n=30$.

or cytoplasm area basis. In P. sulcata, the area of storage bodies in the $\mathrm{D}$ treatment was very small by any method of calculation, whereas in L/D the area occupied was comparable to that of $P$. laevigata in $\mathrm{D}$ or $\mathrm{L} / \mathrm{D}$.

No detectable starch was found in $P$. sulcata in the dark, but was present in large amounts in $\mathrm{L} / \mathrm{D}$ treated material. Only very small quantities of starch were detected in $P$. laevigata, although again there was more present in the L/D treatment irrespective of the method of calculation.

Pyrenoglobuli numbers in $P$. sulcata, with any method of calculation, (Table 3 ) showed lower densities $(P<0.01)$ in dark-stored material. Pyrenoglobuli were clearly distributed towards the outer margin of the pyrenoid matrix in darkstored material of this species. Total pyrenoglobuli numbers in $P$. laevigata appear to be identical in both L/D and D treatments. However, when their numbers are expressed on a wall, cytoplasm, chloroplast or pyrenoid area basis, the dark-stored material always showed a statistically significantly greater pyrenoglobuli density. There were no obvious differences in pyrenoglobuli distribution within the pyrenoid under the two storage conditions in P. laevigata.

\section{DISCUSSION}

The results presented here show that there are a number of qualitative and quantitative changes caused by incubating lichen thalli in continuous darkness or an alternating light/dark regime.
Moreover, although the two Parmelia species contain the same algal genus (Trebouxia), these treatments did not produce identical results. Many of the differences noted here were only reliably detected because quantitative data was available. The use of different methods of expressing such data has also increased the biological comprehensibility of the differences detected.

For both species it is presumed that readily available storage compounds may be utilized under non-photosynthetic conditions, as the material remained sufficiently hydrated during the incubation period to sustain high rates of respiration. Utilization of a reserve product may be assumed to cause a decrease in cross-sectional area and therefore, because of the near radial symmetry of the algal cells, a comparable change in volume.

In both $P$. laevigata and $P$. sulcata, starch present in the chloroplasts following L/D treatment was either reduced or lost after the D treatment, indicating its ready utilization under starvation conditions in both species. $P$. laevigata synthesized little starch under the L/D conditions, suggesting it has little capacity for production of reserve compounds under the conditions employed. However, this species did form cytoplasmic 'storage bodies' with comparable dimensions to those formed by $P$. sulcata in the light. The apparent slight decrease in 'storage body' volume in the dark suggests only limited utilization of reserve materials in $P$. laevigata, whereas $P$. sulcata appeared to have a higher demand for such 
materials, as shown by its higher respiration rate (Table 1).

Pyrenoglobuli have been frequently considered as an energy-generating reserve material, but this has never been directly demonstrated. The decline in pyrenoglobuli numbers in dark-stored $P$. sulcata (Table 2) apparently supports this suggestion. However, the reverse occurred in $P$. laevigata, lower numbers being present after L/D storage. Unfortunately it is not known whether pyrenoglobuli volume or amount changes; numbers alone may be a poor measure of the quantity of reserve material present. The small size of pyrenoglobuli, especially in $P$. laevigata, precludes accurate area measurement at the magnification required for comparison and measurement of other cellular structures. The comment of Ascaso et al. (1988) that density of staining may partly reflect pyrenoglobuli orientation relative to the plane of section, as much as their lipid content, makes estimates of the total amount of pyrenoglobuli material unreliable.

Changes in organelle volume appear to have been rather variable. Chloroplasts were larger in the dark in both species, while mitochondria were larger in the dark in $P$. sulcata but smaller in $P$. laevigata. In both cases the difference between $\mathrm{D}$ and $\mathrm{L} / \mathrm{D}$ dimensions were least in $P$. laevigata, which, like the utilization of potential reserve materials, suggests that it is a less responsive species.

The observed smaller chloroplast cross-sectional area in L/D material agrees with observations made on other plant groups (Kirk and TilneyBassett, 1978) and is the consequence of water efflux. Mitochondria swell when actively respiring and phosphorylating (Lehninger, 1964), especially in the presence of inorganic phosphate. It is not clear whether the swelling observed in the L/D conditions with $P$. laevigata and in D with $P$. sulcata indicates that different conditions enhance respiratory activities in the two species. The apparent utilization of starch reserves and 'storage bodies' in D-treated $P$. sulcata may reflect a period of enhanced respiratory activity in the dark, resulting from the release of respirable reserves. In the dark, $P$. laevigata, due to its lower capacity to form starch in $\mathrm{L} / \mathrm{D}$, might appear to be deficient in respirable reserves. However, the large size of the cytoplasmic 'storage bodies' in this species and presence of numerous pyrenoglobuli, could also be interpreted as indicative of high available energygenerating reserves, causing mitochondrial swelling in both treatments. The failure to synthesize appreciable quantities of starch in $P$. laevigata under the L/D conditions may merely reflect a different pattern of photosynthate partitioning in this species or different light and/or water content requirements. $P$. laevigata appears to be restricted to wet, oceanic conditions, whereas the more desiccation-tolerant $P$. sulcata has a much more wide ranging distribution (Seaward and Hitch, 1982). It is probable that the former species may require a higher thallus water content to sustain active metabolism. Storage at $100 \%$ r.h. may not, therefore, maintain the thallus water content at a sufficient level to permit the build-up or utilization of metabolic reserves.

Direct measurements of respiration and photosynthesis (Table 1) appear to be of little value in supporting hypotheses, based on ultrastructural data, about the availability of respirable reserves. Photosynthetic rates were comparable in the two species, therefore yielding potentially similar amounts of respirable materials. However, respiration rates in $P$. sulcata were more than twice those of $P$. laevigata under all conditions, although there was greater enhancement of respiration in the dark in $P$. laevigata. Unfortunately these measurements represent the gas exchange of the intact lichen, where the majority of the respiratory activity can be presumed to come from the fungal, rather than the algal component, since the former generally represents at least $90 \%$ of the lichen mass. In addition, the ultrastructural data may show the consequence of previous metabolic activity, whereas the gas exchange data relates to the immediate condition of the material. Thus starch may have been consumed in P. sulcata during the D treatment, resulting in insufficient respirable residues to show enhanced respiration when assayed at the end of the period but still sufficient to show enlarged mitochondria.

Another feature in which the two Parmelia species differed in their response to the treatment conditions was that, in $P$. sulcata, D treatment clearly induced an increase in the pyrenoid volume, whereas in $P$. laevigata there was no obvious change. In P. laevigata chloroplasts there were no other detectable protein bodies apart from the pyrenoid but in P. sulcata such protein bodies, while not numerous, increased during treatment. The pyrenoid is generally considered to be mainly formed from insoluble ribulose-bis-phosphate carboxylase enzyme molecules (Griffiths, 1980). It is possible that the non-pyrenoid protein bodies may also constitute an insoluble form of the same enzyme. In other plant cells it is known to crystallize out under stress conditions which result in the loss of water from the chloroplast or which inhibit photophosphorylation (Kwok, Kawashima and Wildman, 1971; Butler et al., 1972; Wrischer, 1973).

These results indicate that changes can occur 
rapidly in the dimensions of many organelles and reserve materials in Trebouxia cells in the two Parmelia species studied here. Future workers should be aware that the conditions immediately prior to fixation can cause significant changes which may not reflect the long-term conditions. The pattern of response to periods of $\mathrm{D}$ or $\mathrm{L} / \mathrm{D}$ incubation differed between $P$. sulcata and $P$. laevigata, with the latter apparently being less responsive to these conditions. Extrapolation from one lichen species to another with the same genus of algal symbiont needs to be made with care.

\section{ACKNOWLEDGEMENTS}

We are pleased to acknowledge that this work was supported by an Anglo/Spanish Joint Research in Higher Education (Acciones Integradas) grant from the British Council and Ministerio de Educacion y Ciencia, Spain and grant number PR 84-0169 from the Comision Asesora de Ciencia y Technologia. We are grateful to $\mathrm{Dr}$ R. M. Brown for valuable discussions and $\mathrm{Mr}$ F. Pinto for technical assistance.

\section{LITERATURE CITED}

Ahmadjian, V., 1982. Alga/fungal symbioses, pp. 179 233. In Progress in Phycological Research, eds F. E. Round and D. J. Chapman, vol 1. Elsevier Biomedical Press, Amsterdam.

Ascaso, C., Brown, D. H. and RapsCh, S., 1985. Ultrastructural studies of desiccated lichens, pp. 259-74. In Lichen Physiology and Cell Biology, ed. D. H. Brown. Plenum Press, London and New York.

1986. The ultrastructure of the phycobiont of desiccated and hydrated lichens. Lichenologist 18, 37-46.

1988. The effect of desiccation on pyrenoid structure in Parmelia laevigata. Lichenologist 20, 31-9.

Ascaso, C. AND Galvan, J., 1976. The ultrastructure of the symbionts of Rhizocarpon geographicum, Parmelia conspersa and Umbilicaria pustulata growing under dryness conditions. Protoplasma 87, 409-18.

Brown, D. H., Ascaso, C. and RapsCh, S., 1987. Ultrastructural changes in the pyrenoid of the lichen Parmelia sulcata stored under controlled conditions. Protoplasma 136, 136- 44.

Butler, W. L., Degreef, J., Roth, T. F. and OelzeKAROW, H., 1972. The influence of carbonyl cyanidem-chlorophenylhydrazine and 3-(3,4 dichlorophenyl)-1,1-dimethylurea on the form of primary thylakoids and the formation of crystalline fibrils in bean leaves partially greened in far-red light. F'ant Physiology 49, 102-4.
Fisher, K. A. and LANG, N. J., 1971. Comparative ultrastructure of cultured species of Trebouxia. Journal of Phycology 7, 155-65.

GrifFITHS, D. J., 1980. The pyrenoid and its role in algal metabolism. Science Progress, Oxford 66, 537-53.

Harris, G. P. and Kershaw, K. A., 1971. Thallus growth and the distribution of stored metabolites in the phycobionts of the lichens Parmelia sulcata and P. physodes. Canadian Journal of Botany 49, 1367 72.

Holopainen, T. H., 1982. Summer versus winter condition of the ultrastructure of the epiphytic lichens Bryoria capillaris and Hypogymnia physodes in central Finland. Annales Botanici Fennici 19, 39-52.

JACOBS, J. B. and Ahmadjian, V., 1969. The ultrastructure of lichens. I. A general survey. Journal of Phycology 5, 227-40.

1971. The ultrastructure of lichens. II. Cladonia cristatella: the lichen and its isolated symbionts. Journal of Phycology 7, 71-82.

KIRK, J. T. O. and TILnEY-BASSETT, R. A. E., 1978. The Plastids. Their Chemistry, Structure, Growth and Inheritance. Elsevier/North Holland Biomedical Press, Amsterdam.

Kwok, S., Kawashima, N. and Wildman, S. G., 1971. Specific effect of ribulose-1,5-diphosphate on the solubility of tobacco fraction 1 protein. Biochimica Biophysica Acta 234, 293-7.

LeHninger, A. L., 1964. The Mitochondrion. Molecular basis of Structure and Function. W. A. Benjamin Inc, New York.

MacFarlane, J. D. and Kershaw, K. A., 1982. Physiological-environmental interactions in lichens. XIV. The environmental control of glucose movement from alga to fungus in Peltigera polydactyla, $P$. rufescens and Collema furfuraceum. New Phytologist 91, 93-101.

REYNOLDS, S., 1963. The use of lead citrate at high $\mathrm{pH}$ as an electron-opaque stain in electron microscopy. Journal of Cell Biology 17, 200-11.

ScotT, M. G. and LaRson, D. W., 1984. Comparative morphology and fine structure of a group of Umbilicaria lichens. Canadian Journal of Botany 62, 1947-64.

Seaward, M. R. D. and Нitch, C. J. B., 1982. Atlas of the Lichens of the British Isles, vol. 1. Institute of Terrestrial Ecology, Cambridge.

Snelgar, W. P., Brown, D. H. and Green, T. G. A., 1980. A provisional survey of the interaction between net photosynthetic rate, respiratory rate, and thallus water content in some New Zealand cryptogams. New Zealand Journal of Botany 18, 247-56.

SPURR, A. R., 1969. A low-viscosity epoxy resin embedding medium for electron microscopy. Journal of Ultrastructural Research 26, 31-43.

WrisCHER, M., 1973. Protein crystallids in the stroma of bean plastids. Protoplasma 77, 141-50. 